〈Research Paper〉

\title{
Photoinitiator-free Photo-reactive Coloration of Wool Fabrics Using C.I. Reactive Black 5
}

\author{
Yuanyuan Dong and Jinho Jang ${ }^{\dagger}$ \\ Department of Nano-Bio Textile Engineering, Kumoh National Institute of Technology, Gumi, Gyeongbuk, Korea
}

(Received: June 5, 2012/Revised: June 18, 2012/Accepted: June 19, 2012)

\begin{abstract}
Compared with conventional adsorption-based coloration, the photoreactions of dyes such as photo-copolymerization and photo-crosslinking under UV irradiation can be employed for the coloration of textiles, which can be carried out without salt addition at room temperature. C.I. Reactive Black 5, a homo-bifunctional reactive dye containing two sulfatoethylsulfone groups, is used as a photo-reactive dye for wool fibers. Upon UV irradiation, the photo-reactive dye was grafted onto wool fabrics without photoinitiators. Since the disulfide bonds in the cystine residues of wool can be easily photodecomposed to active thiyl radicals which initiate the polymerization, the dye can be polymerized to an oligomeric dye of a degree of polymerization of 12 or more. The grafted fabrics reached a grafting yield of $2.3 \%$ o.w.f. and a color yield (K/S) of 18.2 by the photografting of an aqueous dye concentration of $9 \%$ using a UV energy of $25 \mathrm{~J} / \mathrm{cm}^{2}$. Furthermore, the photochemically dyed wool fabric showed higher colorfastness properties to light, laundering and rubbing comparable to conventional reactive dyeing.
\end{abstract}

Keywords: wool, C.I. Reactive Black 5, UV irradiation, photografting, color yield

\section{Introduction}

In conventional dyeing methods involving adsorption and diffusion of dyes into fibers, specific classes of dyes should be applied for different types of fibers because the dyes must have strong affinity towards the fibers for good dyeability and color fastness. The intermolecular interactions between the dyes and wool include ionic bond, covalent bond, hydrogen bond, dipolar interaction, and van der Waals force ${ }^{1,2)}$. For example, wool fibers can be dyed with acid, mordant, metal-complex and reactive dyes. Most of the wool dyeings are carried out at the boil with large amount of electrolytes and auxiliaries for good migration and levelness, resulting in inevitable environment unfriendliness including high volumes of wastewater discharge containing unfixed dyes and additives ${ }^{3)}$. Also the heating of aqueous dye solution and drying results in high energy consumption coupled with heavy carbon-emission load. Therefore, new environmentally-friendly dyeing method need to be developed to replace the adsorptionbased dyeing which can incorporate little or no electrolyte addition, minimal energy consumption and high fixation.

${ }^{\dagger}$ Corresponding author: Jinho Jang (jh.jang@kumoh.ac.kr) Tel.: +82-54-478-7715 Fax.: +82-54-478-7710 (C)2012 KSDF 1229-0033/2012-06/97-105
Also there has been incessant exploration on the 'universal dyeing' which can color all kinds of fibers with same application class of dyes including disperse dyes $^{4,5)}$.

One method is to modify the dyeability of the fibers by engineering the molecular structures of fibers and polymers. The modification includes surface and bulk modification by radiation or chemical treatments. Low-temperature plasma has been confirmed to enhance the hydrophilicity and surface eletrostatic properties of wool fabrics as well as the dyeability ${ }^{6,7)}$.

Corona-treated wool fabrics achieved the same or even better colour exhaustion in comparison to conventional pre-treated wool fabric ${ }^{8)}$. The wool fabric was treated by UV/ozone significantly increased its wettability and dyeability, which was attributed to the oxidation of the cystine linkage on the surface of the fabric and the formation of free-radical species encouraged dye uptake ${ }^{9,10)}$.

Another method is the grafting of different kinds of functional monomers which can modify dyeability. Grafting is essentially the copolymerisation of a monomer/ oligomer to a backbone polymer and new covalent carbon-carbon bonds are formed between graft monomer chains and the polymer surface. The graft polymer 
chains on textile surfaces can possess long-term durability due to strong covalent bonds between the grafted chains and substrates ${ }^{11}$.

For examples, methyl methacrylate (MMA) was grafted onto wool fabric using various initiating systems. Poly(methyl methacrylate) has been grafted onto wool fabric by preirradiation or chemical initiation ${ }^{12)}$. The preirradiated grafted wool exhibited a relatively higher dyeing affinity than that prepared by the chemical method. The grafted wool showed an enhancement in dyeability towards some basic dyes of different size and chemical structure. Dimethylaminopropyl methacrylamide (DMAPMA) was grafted onto PET/wool fabrics by continuous UV irradiation under ambient condition ${ }^{13)}$. The color yield of the modified PET/wool blend fabrics to wool-reactive dyes increased remarkably due to the formation of covalent bonds between secondary amine in the grafted polymer and reactive groups in the dye molecules.

Until now, there has been no research on the direct photografting of dyes onto the wool fabric. In general, radiation grafting can be initiated with the use of ozone $^{14)}, \gamma$ rays $^{15)}$, electron beams ${ }^{16)}$, plasma ${ }^{17)}$, corona discharge $^{18)}$, and UV irradiation ${ }^{19,20)}$. Among them, UV irradiation has been extensively applied for surface graft polymerization of polymers because of facile grafting conditions and less impact on the bulk properties $^{21)}$. UV-induced surface graft polymerization exhibits several advantages, such as fast reaction rate, simple equipment, easy exploitation, low temperature treatment, energy saving, environmentally friendliness and may be the most important, the distribution of grafted chains in a shallow region near the surface ${ }^{22,23)}$.
The photo-reactive coloration may realize the universal dyeing without requiring specific intermolecular interactions and affinity of dyes for the fibers. In previous coloration study, C.I. Reactive Black 5 and acrylic acid binary monomers can be easily grafted onto cotton fabric by continuous UV irradiation under ambient condition without salt ${ }^{24)}$.

In the present paper, a novel UV-induced graft polymerization of C.I. Reactive Black 5 onto wool fabric has been disclosed. Significantly, this continuous dyeing is capable of operating at room temperature without auxiliary addition. In addition, the UV-induced grafting mechanism of C.I. Reactive Black 5 was proposed and verified by ${ }^{1} \mathrm{H}$ NMR, elemental and mass analyses.

\section{Experimental}

\subsection{Materials and chemicals}

Plain weave wool $\left(98 \mathrm{~g} / \mathrm{m}^{2}\right)$ fabrics were used throughout the study. 2-Hydroxy-4'-(2-hydroxyethoxy)-2-methylpropiophenone (Irgacure 2959, Ciba Specialty Chemicals Inc.) was used as a photoinitiator (PI) and Trion X100, a wetting agent, was bought from Yakuri Pure Chemical Co. Ltd (Japan). C.I. Reactive Black 5 (Remazol Black B), supplied by Dystar Texilfarben $\mathrm{GmbH} \&$ Co., was employed with or without purification.

The chemical structures of the photoinitiator and dye are shown in Figure 1.

\subsection{Photografting}

Wool fabric was immersed into an aqueous grafting formulation containing dye, PI and Triton X100. Then the impregnated fabric was squeezed to a wet pick up<smiles>CC(C)(O)C(=O)c1ccc(OCCO)cc1</smiles>

(a)<smiles>Nc1c(N=Nc2ccc(OS(=O)(=O)OCCOS(=O)(=O)O[Na])cc2)c([N+](=O)[O-])cc2cc([N+](=O)[O-])c(N=Nc3ccc(S(=O)(=O)O[Na])cc3)c(O)c12</smiles>

(b)

Figure 1. Molecular structures of (a) Irgacure 2959 and (b) C.I. Reactive Black 5. 
of about $90 \%$ using a padding mangle.

A UV apparatus enclosing a D-bulb (a Fe doped mercury lamp) of $80 \mathrm{~W} / \mathrm{cm}$ intensity was used for UV irradiation. The main spectral output of D-bulb located in the wavelength range of 350 to $400 \mathrm{~nm}$. UV energy was controlled by adjusting the speed and passing cycles of a conveyor belt. After irradiation, the fabrics were thoroughly extracted first with $2 \%$ detergent solution at $60^{\circ} \mathrm{C}$ for $30 \mathrm{~min}$ and subsequently with running water to remove the unreacted dye, PI and soluble homopolymer. Grafting yield $(\mathrm{G} \%)$ was calculated from the following equations respectively:

$$
\mathrm{G} \%=\left(\mathrm{W}_{2}-\mathrm{W}_{1}\right) / \mathrm{W}_{1} \times 100
$$

where, $\mathrm{W}_{1}$ is the weight of the original fabric, and $\mathrm{W}_{2}$ is the weight of UV-irradiated fabric after the extraction.

\subsection{Characterizaiton of the photografted wool surface}

A $400 \mathrm{MHz}{ }^{1} \mathrm{H}$ NMR (Avance Digital 400, Bruker) as a solvent was used to characterize the molecular structures of the C.I. Reactive Black 5 before and after UV irradiation using $\mathrm{D}_{2} \mathrm{O}$. Elemental analysis (EA 1110, Mccoy Co.) was used to measure the contents of sulfur, carbon, hydrogen and nitrogen of the C.I. Reactive Black 5 before and after UV irradiation. Mass spectra (LCQ Deca XP MAX, Thermo Electlon) of the aqueous formulation containing dye and cysteine before and after UV irradiation were obtained for the identification of the polymerized products.

\subsection{The evaluation of coloration}

$\mathrm{K} / \mathrm{S}$ values were calculated from reflectance at $\lambda$ max measured with a reflectance spectrophotometer (Gretag Macbeth, Coloreye 3100). Color yield was evaluated by Kulbelka-Munk equation as the following: $\mathrm{K} / \mathrm{S}=$ $(1-\mathrm{R})^{2} / 2 \mathrm{R}$ where $\mathrm{K}$ is an absorption coefficient, $\mathrm{S}$ is a scattering coefficient, and $\mathrm{R}$ is the reflectance at $\lambda_{\max }$. The colorfastness tests to laundering, rubbing and light irradiation of the dyed fabrics were carried out using a Launder-O-meter (Daelim Engineering, Korea), crock meter (Heungshin Engineering, Korea), and FadeO-meter (Korea Science, Korea) according to $\mathrm{KS} \mathrm{K}$ ISO 105-C01, KS K 0650 and KS K 0700 respectively.

\section{Results and Discussion}

\section{1 ${ }^{1} \mathrm{H}$ NMR analysis}

The NMR spectrum of C.I. Reactive Black 5 before UV irradiation was shown in Figure 2 (a). The benzene protons of the dye were indicated at the peaks of 3, 4, 5, 5', 6 and 6'. The intense signals of 7 and 8 were assigned to the ethylene protons in sulfatoethylsulfone (SES) groups of the dye. The weak peaks of $\mathrm{a}, \mathrm{b}$ and $\mathrm{c}$ were attributed to pristine vinylsulfone (VS) protons.

In the aqueous formulation containing the dye and cysteine, the cysteine was added as photoinitiator in order to enhance the formation of radicals to simulate the wool cystine. And the weight ratio of dye and cysteine was $5: 1$. With a UV energy of $25 \mathrm{~J} / \mathrm{cm}^{2}$ (Figure 2 (b)), there appeared new peaks of $3^{\prime}$ and 4', which were due to the cleavage of the two C-S bonds $(90 \mathrm{~kJ} / \mathrm{mol})$ in the dye structure under UV irradiation $^{25)}$.

Moreover, the intensity of ethylene protons in SES groups decreased with introduction of some new protons peaks of $11,12,13,14,15$ and 16 . The VS groups are expected to be rapidly reacted into four different forms of cyclized [2+2] or linear dimers ${ }^{26-30)}$.

Interestingly, poly(vinylsulfone) dyes with high degree of polymerization were also produced by UV irradiation. According to the peak area calculation of the ${ }^{1} \mathrm{H}$ NMR spectrum, about $55 \%$ of the dye was found to be photocyclized or polymerized after UV irradiation. Since Black 5 is a bifunctional reactive dye, the crosslinked and polymerized dye network is expected to be formed most probably. The methine (11) and methylene (12) protons of the polymerized dye units can have many different magnetic environments, influenced not only by head to head or head to tail configurations but also by the configurational sequences such as meso and racemic connections. The observed spectra (b insert) seemed to indicate the presence of meso and racemic configurations. An example of polymerized dye network showing head-to-tail configuration was given in Scheme 1. The new peaks 13 and 14 in different configurations may have different chemical shifts, accordingly assigned to 13,13 ', 14, 14' and 14". Furthermore, the hydroxyl proton in hydroxyethyl sulfone (HES) group suggested the facile hydrolysis ${ }^{31)}$ 


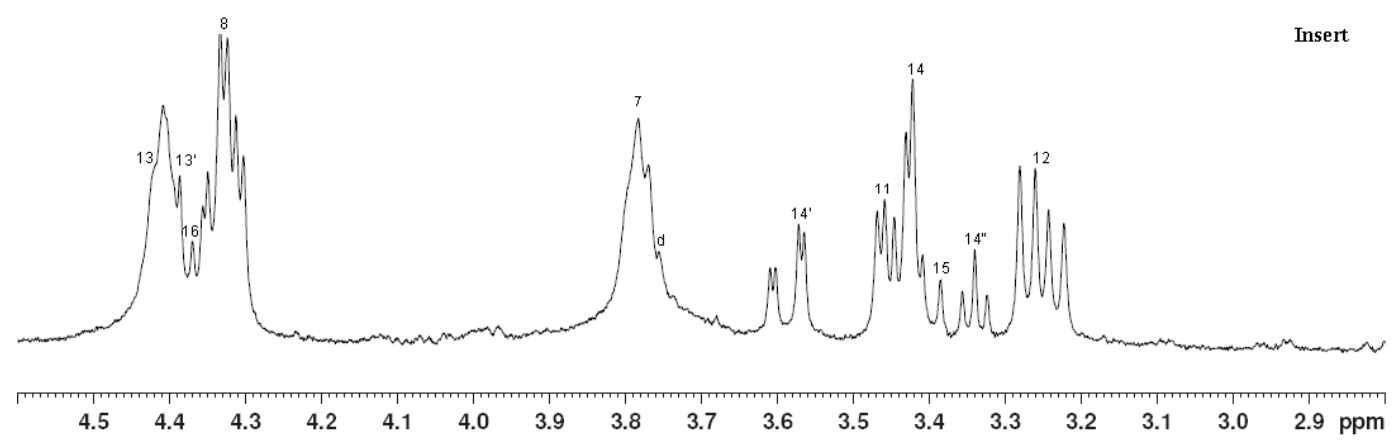

(b)

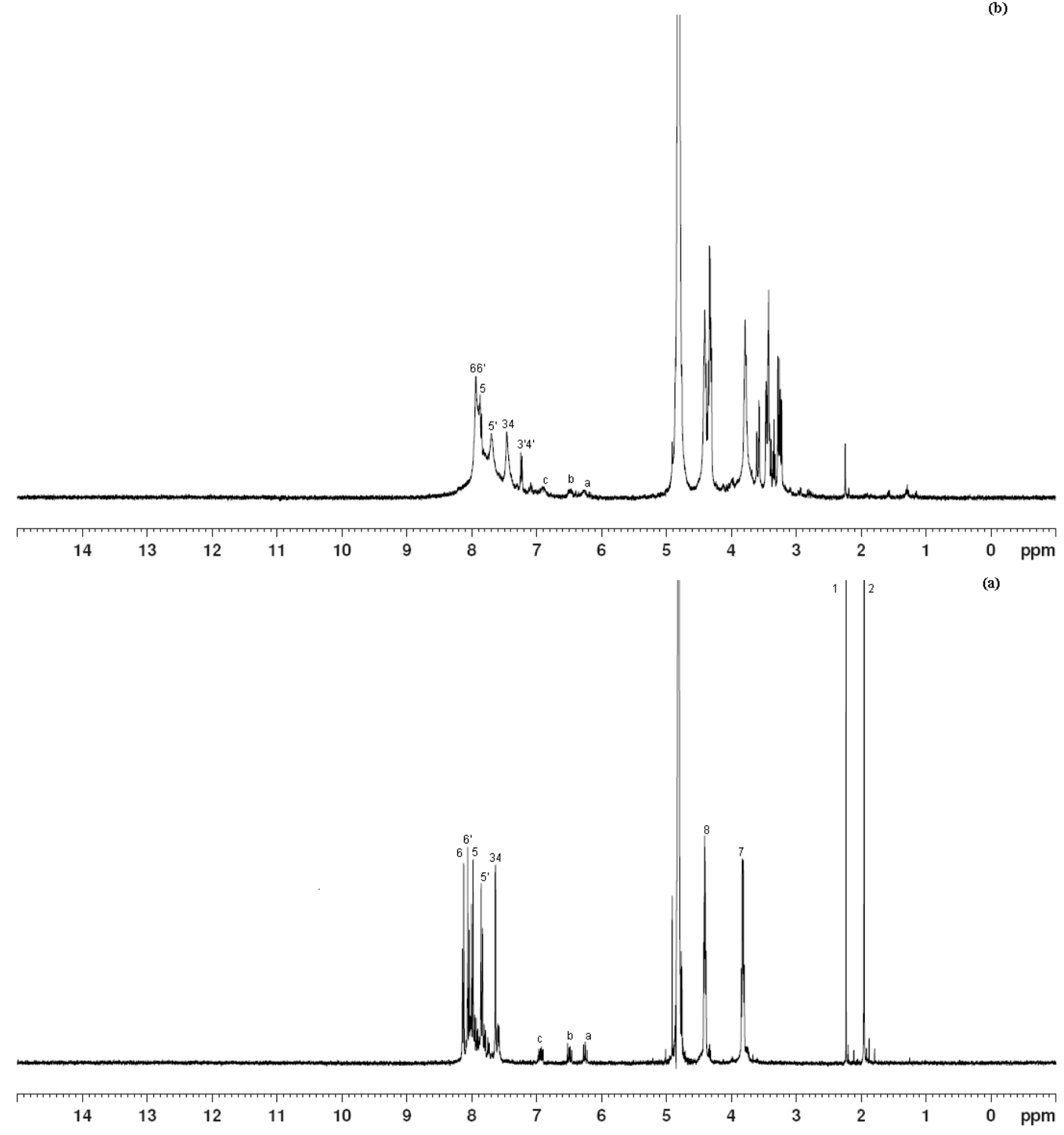

Figure 2. ${ }^{1} \mathrm{H}$ NMR spectra of the dye (a) and (b) after UV irradiation of $25 \mathrm{~J} / \mathrm{cm}^{2}$.

of the dyes under UV irradiation. Therefore, the photopolymerization of the dye can be proved by ${ }^{1} \mathrm{H}$ NMR analysis. The VS reactive group generated from the SES dye under UV light can be photochemically converted to VS, which can be cyclized to dimers or polymerized to polymer network initiated by the thiyl radicals from the wool surface. It would be significantly important for the UV-induced coloration for wool. 
<smiles>Nc1c(N=Nc2ccc(OS(=O)(=O)O[Na])cc2)c([N+](=O)[O-])cc2cc([N+](=O)[O-])c(N=Nc3ccc(OS(=O)(=O)O[Na])cc3)c(O)c12</smiles>

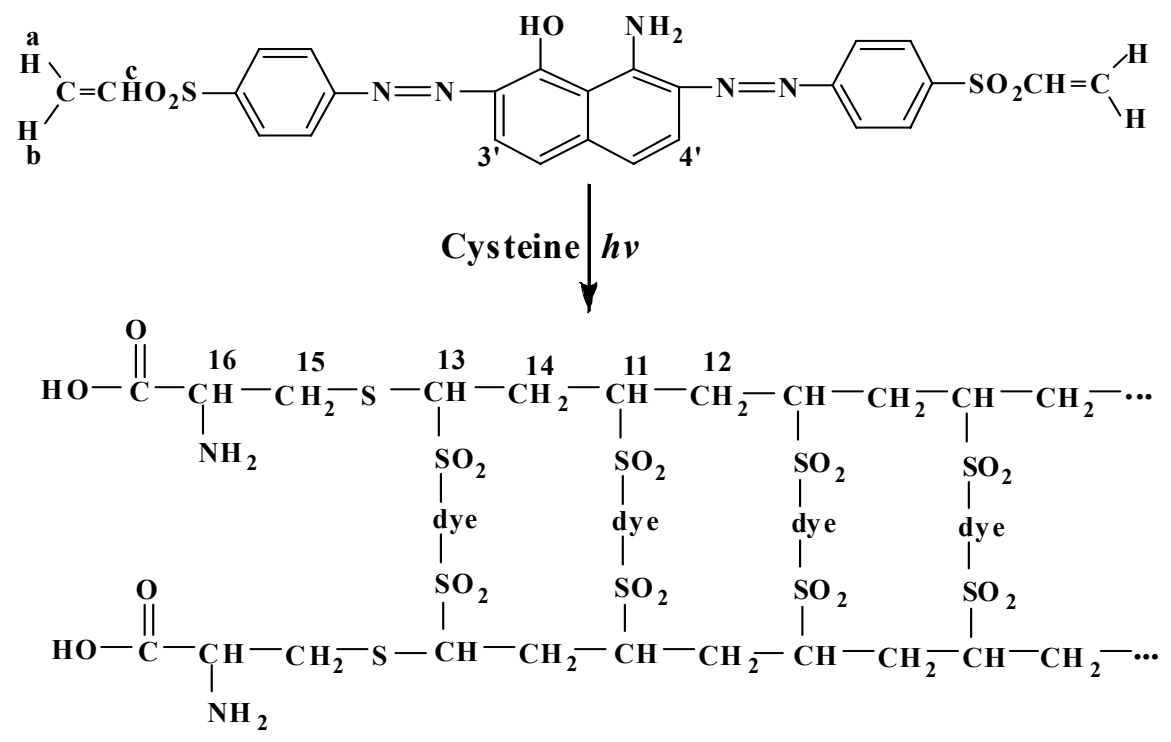

Scheme 1. Proposed photoreaction of C.I. Reactive Black 5 with cysteine

\subsection{Mass analysis}

In order to elucidate the mechanism of C.I. Reactive Black 5 polymerization, mass spectroscopic analysis was carried out to identify the polymerized product of the reactive dye. Mass spectra of the aqueous formulation containing dye and cysteine were analyzed before and after UV irradiation. The cysteine was added as a photoinitiator in order to simulate the formation of radicals in the wool. The molecular weight of the dye (M) is $991 \mathrm{~g} / \mathrm{mol}$. With the lost of four $\mathrm{Na}^{+}$ions, the molecular weight of $\left[\mathrm{M}-4 \mathrm{Na}^{+}\right] / 4$ is $225 \mathrm{~g} / \mathrm{mol}$, but the signal corresponding to $\left[\mathrm{M}-4 \mathrm{Na}^{+}\right] / 4$ was observed at $\mathrm{m} / \mathrm{z} 234$ in Figure 3(a), where the difference may be resulted from the hydrated water in the molecular ion. At a UV energy of $5 \mathrm{~J} / \mathrm{cm}^{2}$, the three new signals at the $\mathrm{m} / \mathrm{z}$ of 170,381 and 465 were attributed to $\left[\mathrm{M}-2 \mathrm{SO}_{3} \mathrm{Na}-2 \mathrm{Na}^{+}-2 \mathrm{H}^{+}\right] / 4$, $\left[\mathrm{M}-2 \mathrm{SO}_{3}\right.$ $\left.\mathrm{Na}-2 \mathrm{Na}^{+}\right] / 2$ and $\left[\mathrm{M}-2 \mathrm{HSO}_{4} \mathrm{Na}-2 \mathrm{SO}_{3} \mathrm{Na}-\mathrm{SO}_{2} \mathrm{CHCH}_{2}-\mathrm{H}^{+}\right]$ respectively because the weak $\mathrm{C}-\mathrm{S}$ bond $(90 \mathrm{~kJ} / \mathrm{mol})$ can be easily cleaved by the UV irradiation ${ }^{24)}$. Three new signals at the $\mathrm{m} / \mathrm{z}$ of 527,611 and 695 were corresponded to the linked dimers of $\left[\mathrm{M}-\mathrm{HSO}_{4} \mathrm{Na}-3 \mathrm{Na}^{+}\right] / 3$, [M$\left.2 \mathrm{HSO}_{4} \mathrm{Na}-\mathrm{SO}_{2} \mathrm{CHCH}_{2}-2 \mathrm{Na}^{+}\right] / 2$, and $\left[\mathrm{M}-2 \mathrm{HSO}_{4} \mathrm{Na}-2 \mathrm{Na}^{+}\right] / 2$ respectively. The peak located at the $\mathrm{m} / \mathrm{z}$ of 1,562 can be attributed to $2\left[2 \mathrm{M}-2 \mathrm{HSO}_{4} \mathrm{Na}-6 \mathrm{SO}_{3} \mathrm{Na}-3 \mathrm{SO}_{2} \mathrm{CHCH}_{2}\right.$ $\left.-2 \mathrm{Na}^{+}\right] / 2$, which is a tetramer.

Under a UV energy of $25 \mathrm{~J} / \mathrm{cm}^{2}$ (Figure 3(c)), the new peaks at the $\mathrm{m} / \mathrm{z}$ of 1,782 can be assigned to $3\left[4 \mathrm{M}-8 \mathrm{HSO}_{4} \mathrm{Na}-5 \mathrm{SO}_{3} \mathrm{Na}-7 \mathrm{SO}_{2} \mathrm{CHCH}_{2}-3 \mathrm{Na}^{+}\right] / 3$, while an $\mathrm{m} / \mathrm{z}$ of 1,874 corresponded to $3\left[4 \mathrm{M}-8 \mathrm{HSO}_{4} \mathrm{Na}-5 \mathrm{SO}_{3} \mathrm{Na}-\right.$ $\left.6 \mathrm{SO}_{2} \mathrm{CHCH}_{2}-3 \mathrm{Na}^{+}\right] / 3$. The other new signal at the $\mathrm{m} / \mathrm{z}$ of 1,965 can be explained by $3\left[4 \mathrm{M}-8 \mathrm{HSO}_{4} \mathrm{Na}-5 \mathrm{SO}_{3} \mathrm{Na}-\right.$ $\left.5 \mathrm{SO}_{2} \mathrm{CHCH}_{2}-3 \mathrm{Na}^{+}\right] / 3$. Since there may be the insoluble fraction in $\mathrm{D}_{2} \mathrm{O}$ due to the presence of the crosslinked dye network, it can be concluded that the dye can be photopolymerized to oligomeric dyes containing 12 repeating units or more under the experimental condition.

\subsection{UV energy and $\mathrm{PI}$ concentration}

Figure 4 illustrated that the $\mathrm{G} \%$ and $\mathrm{K} / \mathrm{S}$ values increased proportionally with increasing UV energy. 

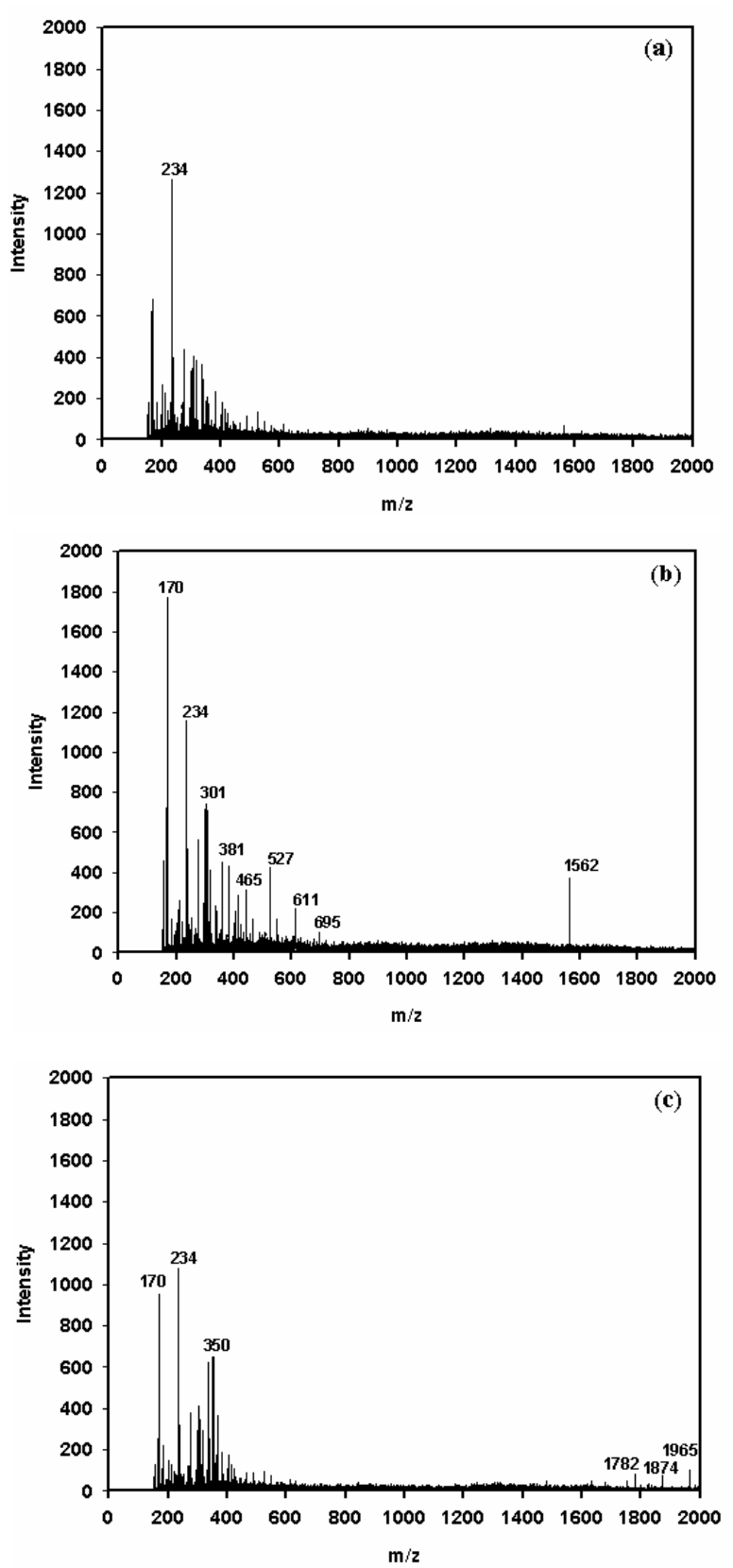

Figure 3. Mass spectra of the dye (a) and after UV irradiation of (b) $5 \mathrm{~J} / \mathrm{cm}^{2}$ and (c) $25 \mathrm{~J} / \mathrm{cm}^{2}$.

However, the PI concentration did not have significantly effect on $\mathrm{G} \%$ and $\mathrm{K} / \mathrm{S}$ (Table 1) probably resulting from the presence of disulfide bonds of the cystine residue in wool capable of producing active free radical under UV irradiation, while the added photoinitiator may promote the homopolymerization rather than graft polymerization. Therefore, the dye can be initiated by thiyl radicals originated from the cysteine $^{32)}$ and hence the photo-grafting of C.I. Reactive Black 5 onto wool fabric can be carried out without

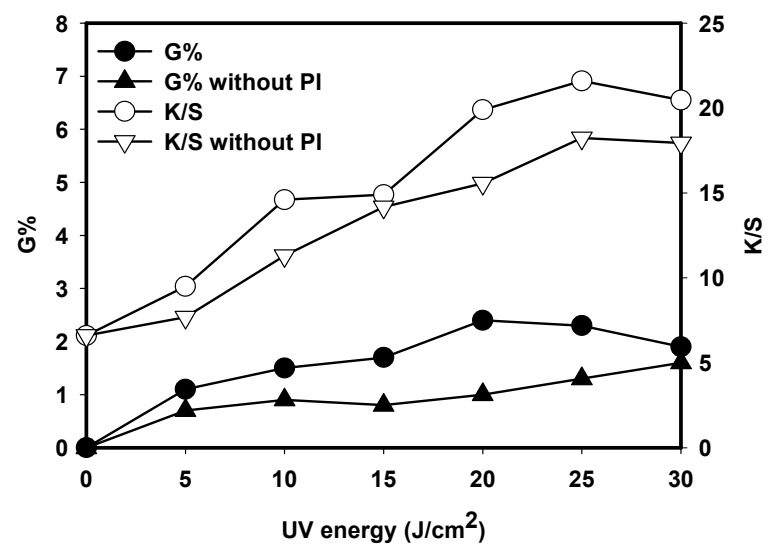

Figure 4. The effect of UV energy on $\mathrm{G} \%$ and $\mathrm{K} / \mathrm{S}$ (photoinitiator concentration: 3\%, dye concentration: $9 \%$ ).

Table 1. The effect of photoinitiator concentration on $\mathrm{G} \%$ and $\mathrm{K} / \mathrm{S}$

\begin{tabular}{ccc}
\hline PI concentration (\%) & G\% & K/S \\
\hline \hline 0 & 2.0 & 16.0 \\
1 & 2.1 & 16.7 \\
3 & 2.3 & 18.2 \\
5 & 2.2 & 17.3 \\
7 & 2.1 & 17.3 \\
9 & 2.1 & 17.1 \\
\hline
\end{tabular}

(UV energy: $25 \mathrm{~J} / \mathrm{cm}^{2}$, dye concentration: $9 \%, \mathrm{pH} 6$ )

PI under UV irradiation.

Moreover, the $\mathrm{G} \%$ and $\mathrm{K} / \mathrm{S}$ increased until a UV energy of $25 \mathrm{~J} / \mathrm{cm}^{2}$ and then leveled off. Higher UV energy is expected to increase the number of surface radicals, resulting in higher initiation efficiency for the photopolymerization. Beyond the UV energy of $25 \mathrm{~J} / \mathrm{cm}^{2}$, the thiyl radicals cannot be increased more due to the limited cystine content in wool keratin.

\subsection{Dye concentration}

The increase in dye concentration can promote the rate of the dye polymerization. The graft yield and $\mathrm{K} / \mathrm{S}$ value increased with increasing dye concentration (Figure 5). However, the dye concentration above 9\% may attribute to the blocking of the UV light required for the scission of cysteine, resulting in the dominant hompolymerization of the dyes over the photografting. The photografting mechanism under acidic condition was suggested in Scheme 2. Under UV irradiation the disulfide bonds in the wool cysteine were cut off and 
SES was converted to VS, where the generated wool macro radicals initiated the VS to polymerize or crosslink to form the grafted dye networks.

\subsection{Color fastness properties}

The color fastness of the dyed fabrics to washing, rubbing and light were shown in Table 2. The K/S values of the dyed wool fabrics $(3,5)$ by conventional dyeing in the presence of salt was low except the one at boil for one hour (4), indicated that vinyl sulfone reactive group can react with wool at high temperature. Compared with the conventional dyeing methods, the color yield of the photografted wool was a little higher than that of the common reactive dyeing

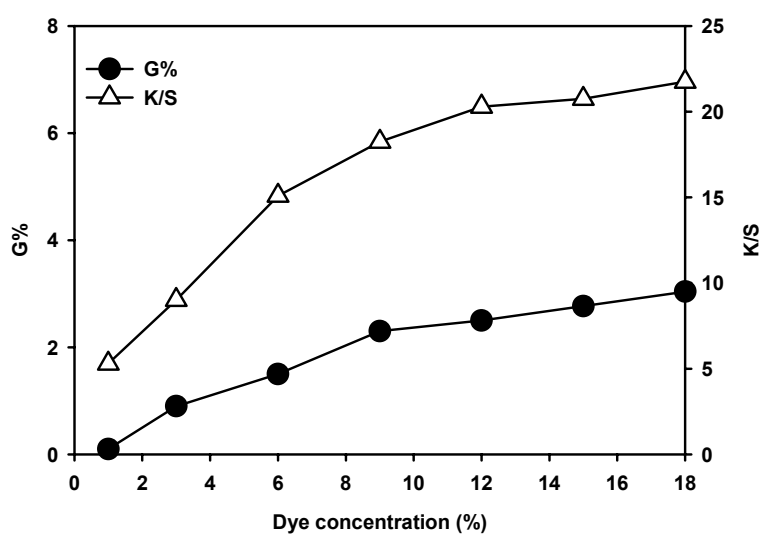

Figure 5. The effect of dye concentration on $\mathrm{G} \%$ and $\mathrm{K} / \mathrm{S}$ (no photoinitiator, UV energy: $25 \mathrm{~J} / \mathrm{cm}^{2}$ ).
(4) which was thermally reacted by the nucleophilic addition of the vinyl sulfone reactive dyes. The wool fabrics (5) dyed with alkaline condition showed lower dyeability and color fastness to shade change presumably due to possible alkaline degradation of the wool protein. While the washing, light and rubbing fastness properties of the photochemically colored wool were good enough and similar to those of the reactive dyeing, the shade change of the photo-reactively colored fabrics was excellent, indicating the presence of polymerized and crosslinked dye network.

\section{Conclusions}

The UV-induced photografting of C.I. Reactive Black 5 onto wool fabric can be carried out in the absence of a photoinitiator at ambient temperature due to the thiyl radicals generated from the photoscission of the disulfide bond of the cystein residue in wool. According to the peak area calculation of the ${ }^{1} \mathrm{H}$ NMR spectrum, about $55 \%$ of the dye was found to be photocyclized or polymerized after UV irradiation.

The grafting yield and color yield for the grafted fabrics depended on photografting conditions, such as UV energy, photoinitiator and dye concentrations. In addition, mass, ${ }^{1} \mathrm{H}$ NMR, elemental analyses were used to assess the photografting mechanism.

Furthermore, the washing, rubbing and light fastness
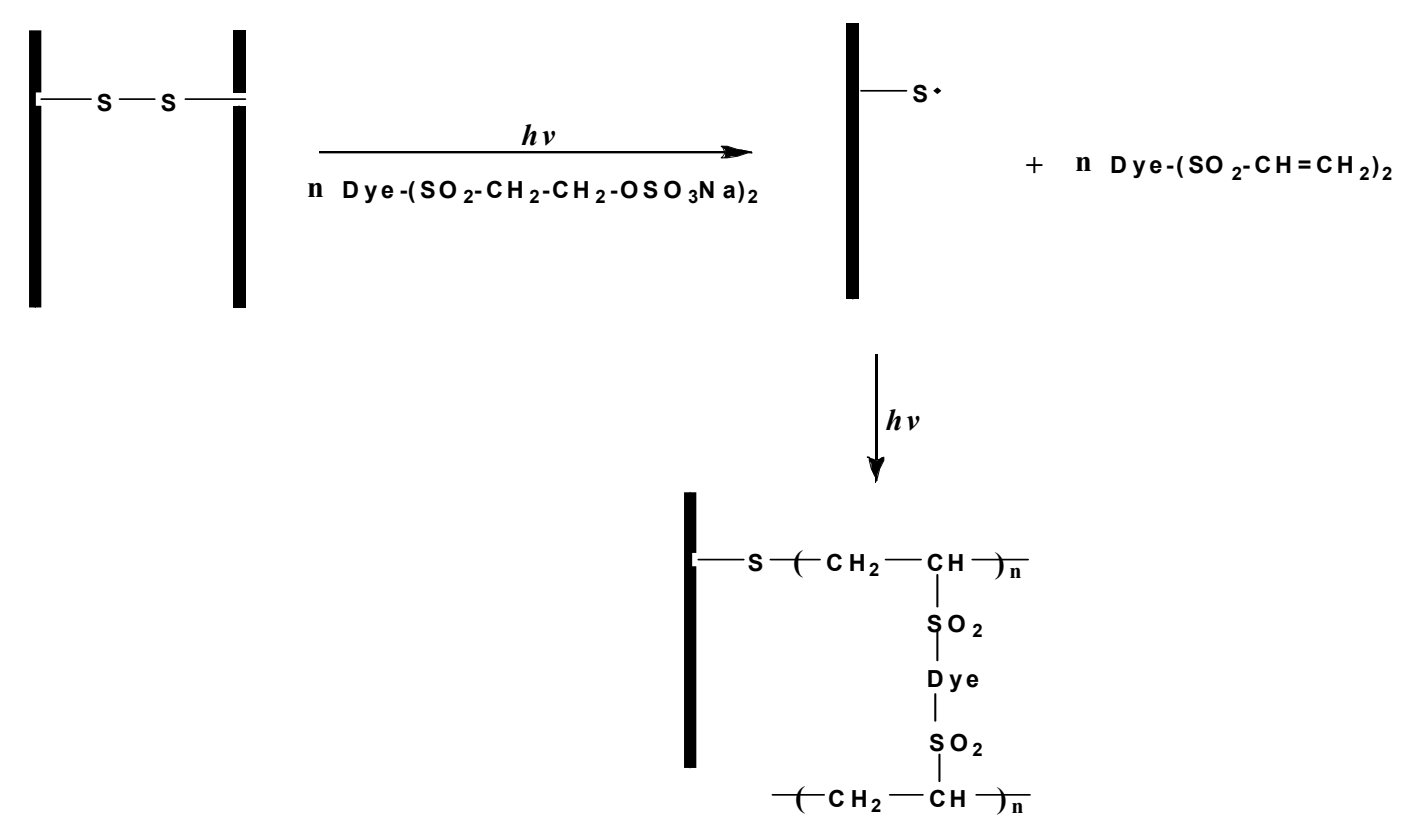

Scheme 2. Photografting mechanism of C.I. Reactive Black 5 onto wool fabric 
Table 2. Colorfastness of the dyed fabrics to laundering, rubbing and light irradiation

\begin{tabular}{|c|c|c|c|c|c|c|c|c|c|c|c|}
\hline & \multirow{3}{*}{$\mathbf{K} / \mathbf{S}$} & \multicolumn{7}{|c|}{ Laundering } & \multicolumn{2}{|c|}{ Rubbing } & \multirow{3}{*}{ Light } \\
\hline & & \multirow{2}{*}{$\begin{array}{l}\text { Shade } \\
\text { change }\end{array}$} & \multicolumn{6}{|c|}{ Stain } & \multirow{2}{*}{ dry } & \multirow{2}{*}{ wet } & \\
\hline & & & wool & acryl & PET & nylon & cotton & acetate & & & \\
\hline Black ${ }^{1}$ & 18.2 & 5 & 5 & 5 & $4-5$ & $4-5$ & $4-5$ & $4-5$ & $4-5$ & $4-5$ & 3 \\
\hline Black ${ }^{2}$ & 2.2 & 3.5 & 5 & 5 & $4-5$ & $4-5$ & $4-5$ & $4-5$ & $4-5$ & $4-5$ & 3 \\
\hline Black ${ }^{3}$ & 2.3 & 4.5 & $4-5$ & $4-5$ & $4-5$ & $4-5$ & 4 & $4-5$ & 5 & 5 & 3 \\
\hline Black ${ }^{4}$ & 14.0 & 4 & $4-5$ & 5 & $4-5$ & $4-5$ & $4-5$ & $4-5$ & 4 & 4 & 3 \\
\hline Black ${ }^{5}$ & 3.5 & 1 & $4-5$ & 5 & $4-5$ & $4-5$ & $4-5$ & $4-5$ & 4 & 5 & 3 \\
\hline
\end{tabular}

1: $\mathrm{pH}$ 6, 9\%o.w.b. (dye), $30^{\circ} \mathrm{C}, \mathrm{UV}$ energy: $25 \mathrm{~J} / \mathrm{cm}^{2}$

2: $\mathrm{pH} 6,3 \%$ o.w.m. (PI), $9 \%$ o.w.b. (dye), $20: 1,30^{\circ} \mathrm{C}$ for $60 \mathrm{~min}$

3: $\mathrm{pH} 6,9 \%$ o.w.b. (dye), $20: 1,30^{\circ} \mathrm{C}$ for $60 \mathrm{~min}$

4: $\mathrm{pH} 6,1 \%$ o.w.f. (dye), $20: 1,100^{\circ} \mathrm{C}$ for $60 \mathrm{~min}$

5: pH 10, $1 \%$ o.w.f. (dye), $20: 1,60^{\circ} \mathrm{C}$ for $60 \mathrm{~min}$

of photo-reactively colored wool fabric were good enough comparable to the conventional dyeing, which made an alternative coloration process of energy- efficiency and environmental friendliness. This novel approach may substantiate 'universal dyeing' concept which a single class of photo-reactive dyes can color almost all fibres.

\section{Acknowledgement}

This research was supported by Basic Science Research Program through the National Research Foundation of Korea (NRF) funded by the Ministry of Education, Science and Technology (2011-0026099).

\section{References}

1. R. M. Christie, R. R. Mather and R. H. Wardman, "The Chemistry of Colour Application", Blakwell, USA, pp.98-108, 2000.

2. D. M. Lewis, "Wool Dyeing", Society of Dyers and Colourists, UK, pp.176-253, 1992.

3. R. M. Christie, "Environmental Aspects of Textile Dyeing”, The Textile Institute and Woodhead, England, pp.83-138, 2007.

4. P. Suwanruji, H. S. Freeman and D. Zhao, Studies toward a Universal Dye for Textile Fibres, Color. Technol., 120, 220(2004).

5. D. M. Lewis, Coloration in the Next Century, Rev. Prog. Coloration, 29, 23(1999).

6. C. W. Kan, K. Chan, C. W. M. Yuen and M. H.
Miao, The Effect of Low-temperature Plasma on the Chrome Dyeing of Wool Fibre, J. Materials Processing Technol., 82, 122(1998).

7. C. W. Kan, K. Chan, C. W. M. Yuen and M. H. Miao, Surface Properties of Low-temperature Plasma Treated Wool Fabrics, J. Materials Processing Technol., 83, 180(1998).

8. D. Fakin, A. Ojstrsek and S. Benkovic, The Impact of Corona Modified Fibers' Chemical Changes on Wool Dyeing, J. Materials Processing Technol., 209, 584(2009).

9. M. N. Micheal and N. A. El-Zaher, Efficiency of Ultraviolet/Ozone Treatments in the Improvement of the Dyeability and Light Fastness of Wool, $J$. Appl. Polym. Sci., 90, 3668(2003).

10. R. Atav and A. Yurdakul, Effect of the Ozonation Process on the Dyeability of Mohair Fibres, Color. Technol., 127, 159(2011).

11. A. Bhattacharya and B. N. Misra, Grafting: A Versatile Means to Modify Polymers Techniques, Factors and Applications, Prog. Polym. Sci., 29, 767(2004).

12. A. M. Naggar, M. M. Marie, E. H. Gendy and A. A. Miligy, Dyeing, Moisture Regain and Mechanical Properties of Wool Fabric Grafted with PMMA by Chemical and Radiation-grafted Methods, Radiat. Phys. Chem., 47, 623(1996).

13. Y. Y. Dong, W. S. Lyoo and J. H. Jang, Union Dyeing of the Photografted PET/Wool Blend Fabrics with Dimethylaminopropyl Methacrylamide, 
Fiber Polym., 11, 213(2010).

14. E. Partouche, D. Waysbort and S. Margel, Surface Modification of Crosslinked Poly(Styrene-divinyl benzene) Micrometer-sized Particles of Narrow Size Distribution by Ozonolysis, J. Colloid Interface Sci., 294, 69(2006).

15. Z. Xu, Y. Huang, C. Zhang, L. Liu, Y. Zhang and L. Wang, Effect of $\gamma$-ray Irradiation Grafting on the Carbon Fibers and Interfacial Adhesion of Epoxy Composites, Composites Sci. Technol., 67, 3261(2007).

16. A. Vahdat, H. Bahrami, N. Ansari and F. Ziaie, Radiation Grafting of Styrene onto Polypropylene Fibres by a $10 \mathrm{MeV}$ Electron Beam, Radiat. Phys. Chem., 76, 787(2007).

17. M. Okubo, M. Tahara, N. Saeki and T. Yamamoto, Surface Modification of Fluorocarbon Polymer Film for Improved Adhesion using Atmospheric-pressure Nonthermal Plasma Graft-polymerization, Thin Solid Films, 516, 6592(2008).

18. J. Lei, M. Shi and J. Zhang, Surface Graft Copolymerization of Hydrogen Silicone Fluid onto Fabric Through Corona Discharge and Water Repellency of Grafted Fabric, Eur. Polym. J., 36, 1277(2000).

19. F. C. Loh, K. L. Tan, E. T. Kang, K. G. Neoh and M. Y. Pun, Near-UV Radiation Induced Surface Graft Copolymerization of Some $\mathrm{O}_{3}$-pretreated Conventional Polymer Films, Eur. Polym. J., 31, 481(1995).

20. J. Jang and Y. Jeong, Flame-retardant Finish of Cotton Fabrics Using UV-curable Phosphorouscontaining Monomers, Textile Coloration and Finishing(J. Korean Soc. Dyers \& Finishers), 20, 8(2008).

21. K. H. Hong, N. Liu and G. Sun, UV-induced Graft Polymerizaiton of Acrylamide on Cellulose by using Immobilized Benzophenone as Photo-initiator, Eur. Polym. J., 45, 1443(2009).

22. A. M. Shanmugharaj, J. K. Kim and S. H. Ryu, Modificaiton of Rubber Surface by UV Surface Grafting, Appl. Surf. Sci., 252, 5714(2006).
23. S. Hu, X. Ren, M. Bachman, C. E. Sims, G. P. Li and N. Allbritton, Surface Modification of Poly (dimethylsiloxane) Microfluidic Devices by Ultraviolet Polymer Grafting, Anal. Chem., 74, 4117 (2002).

24. Y. Y. Dong and J. Jang, Novel Coloration of Cotton Fabrics by UV-induced Photografting of Reactive Black 5 and Acrylic Acid, Textile Coloration and Finishing(J. Korean Soc. Dyers \& Finishers), 23, 11(2011).

25. J. Xue, L. Chen and H. Wang, Degradation Mechanism of Alizarin Red in Hybrid Gas-Liquid Phase Dielectric Barrier Discharge Plasmas: Experimental and Theoretical Examination, Chem. Eng. J., 138, 120(2008).

26. D. Meadows and J. Gervay-Hague, Vinyl Sulfones: Synthetic Preparations and Medicinal Chemistry Applications, Med. Res. Rev., 26, 793(2006).

27. E. A. Bekturov, V. A. Frolova and G. K. Mamytbekov, Swelling of Poly(2-methyl-5-vinylpyridine) Gel in Linear Sodium Poly(vinylsulfonate) Solution, Macromol. Chem. Phys., 199, 1071(1998).

28. H. S. Choe, J. Giaccai, M. Alamgir and K. M. Abraham, Preparation and Characterization of Poly (vinyl sulfone) and Poly(vinylidene fluoride)-Based Electrolytes, Electrochim. Acta, 40, 2289(1995).

29. J. Chen, H. Luo and W. Cao, Interaction of Diazoresins and Sulfonate Containing Polyelectrolytes, Polym. Int., 49, 382(2000).

30. N. Inagaki, S. Tasaka and Y. Goto, Surface Modification of Poly(tetrafluoroethylene) Film by Plasma Graft Polymerization of Sodium Vinylsulfonate, $J$. Appl. Polym. Sci., 66, 77(1997).

31. D. M. Lewis, "Colour and Textile Chemistry", AATCC, pp.1-31, 2008.

32. X. Bingshe, N. Mei, W. Liqiao, H. Wensheng and L. Xuguang, The Structural Analysis of Biomacromolecule Wool Fiber with Ag-loading $\mathrm{SiO}_{2}$ Nanoantibacterial Agent by UV Radiation, J. Photochem. Photobiol. A: Chem., 188, 98(2007). 